\title{
Penetração e Colonização de Acidovorax avenae subsp. citrulli em Folhas, Frutos e Sementes de Melão Amarelo
}

\author{
Edson B. Silva Neto ${ }^{1 *}$, Elineide B. Silveira' ${ }^{1}$ Rosa L. R. Mariano ${ }^{2 * *}$, Neusa L. Nogueira ${ }^{3}$, \\ Mônica L. Rossi ${ }^{3}$ \& Liliana A. Santos ${ }^{1 *}$ \\ ${ }^{1}$ UFRPE, Depto. Biologia/Microbiologia, e-mail: edborgesneto@uol.com.br; ${ }^{2}$ UFRPE, Depto. de Agronomia/ \\ Fitossanidade, CEP 52171-030, Recife, PE; ${ }^{3}$ CENA, USP, Cx. Postal 96, CEP 13400-970, Piracicaba, SP
}

(Aceito para publicação em 27/10/2005)

Autor para correspondência: Elineide B. Silveira

SILVA NETO, E.B., SILVEIRA, E.B., MARIANO, R.L.R., NOGUEIRA, N.L., ROSSI, M.L. \& SANTOS, L.A. Penetração e colonização de Acidovorax avenae subsp. citrulli em folhas, frutos e sementes de melão Amarelo. Fitopatologia Brasileira 31:084-088. 2006.

\section{RESUMO}

Folhas, frutos e sementes de melão (Cucumis melo) Amarelo foram inoculados com Acidovorax avenae subsp. citrulli (Aac1) com o objetivo de estudar a colonização e penetração desse patógeno, utilizando microscopia eletrônica de varredura. Nas folhas coletadas 24, 48, 72, 96 e 120 h após a inoculação foram observadas células bacterianas agregadas e interligadas por fibrilas e muito raramente isoladas. Células bacterianas foram localizadas predominantemente nos flanges cuticulares da epiderme abaxial, na base dos tricomas tectores, próximas aos estômatos diacíticos e no interior dos poros estomáticos. Nos frutos com 37 dias de idade, 24 h após a inoculação, bactérias foram observadas na superfície e concentradas ao redor de estômatos e lenticelas, e nas amostras com 48 h, na polpa do fruto. Nas demais amostras (72 e 96 h) foram encontradas poucas ou até mesmo nenhuma bactéria na superfície dos frutos. Nos frutos com 51 dias de idade foi constatada uma expressiva colonização da superfície, estômatos e lenticelas até 72 h após a inoculação. $\mathrm{Na}$ polpa, a bactéria só foi encontrada nas amostras com 96 h. Os resultados sugerem que A. avenae subsp. citrulli penetrou nos frutos através de estômatos e lenticelas. Nas sementes a bactéria colonizou tegumentos interno e externo, embrião e endosperma.

Palavras-chave adicionais: microscopia eletrônica de varredura, mancha-aquosa, Cucumis melo, ecologia

\begin{abstract}
Penetration and colonization of Acidovorax avenae subsp. citrulli in leaves, seeds and fruits of melon type Yellow Leaves, fruits and seeds of melon (Cucumis melo) type Yellow were inoculated with Acidovorax avenae subsp. citrulli (Aac1) in order to study the penetration and colonization of this pathogen using scanning electron microscopy. Leaves sampled at 24, 48, 72, 96 and $120 \mathrm{~h}$ after inoculation showed clusters of bacterial cells interconnected by fibrils, and very rarely isolated. Bacterial cells were located mainly on the cuticular flange of the abaxial epidermis, on the base of tector trichomes, near the diacytic stomata, and inside the stomat pores. Twenty-four hours after inoculation bacteria were observed mainly on the surface of 37 day-old fruits concentrated around stomata and lenticels; after 48 h bacteria were detected in the fruit pulp as well. In the other samples (72 and $96 \mathrm{~h}$ ) few or no bacteria were found on fruit surfaces. Fruits 51 days old showed expressive colonization of the surface, stomata and lenticels until $72 \mathrm{~h}$ after inoculation. The pathogen was only found in the pulp of the 96-hour samples. These results suggest that $A$. avenae subsp. citrulli penetrated the fruits through the stomata and lenticels. In seeds, the bacteria colonized the internal and external teguments, embryo and endosperm.
\end{abstract}

Additional keywords: scanning electron microscopy, fruit blotch, Cucumis melo, ecology.

A região Nordeste destaca-se como maior produtora de melão (Cucumis melo L.) no Brasil, tendo sido responsável em 2002 por 94,7\% do melão produzido no país. O pólo Rio Grande do Norte-Ceará contribuiu com $82 \%$ da produção do Nordeste e 77,7\% da produção brasileira (IBGE, 2002). A mancha-aquosa causada pela bactéria Acidovorax avenae subsp. citrulli (Schaad et al.) Willems et al. é um problema para a cultura do meloeiro no Nordeste, principalmente nos estados do Rio Grande do Norte e Ceará.

\footnotetext{
*Bolsista PIBIC/CNPq

***Bolsista produtividade $\mathrm{CNPq}$
}

Estimam-se perdas em torno de 40 a 50\%, podendo atingir $100 \%$ em períodos chuvosos (Sales Júnior \& Menezes, 2001). No Nordeste, essa doença em melão foi primeiramente identificada no Estado do Rio Grande do Norte, em 1997, por Assis et al. (1999) e, posteriormente, no Ceará (Santos \& Viana, 2000), Pernambuco (Mariano \& Silveira, 2004) e Bahia (Mariano et al., 2004).

Os sintomas da mancha-aquosa nas folhas caracterizam-se por manchas necróticas com ou sem a presença de halo, podendo crescer e coalescer. Nos frutos maduros antes da colheita, onde os sintomas são mais 
visíveis, a casca apresenta manchas aquosas com ou sem a presença de halo e internamente, a polpa apresenta-se marrom-avermelhada, atingindo as sementes que podem ser contaminadas externamente e internamente. Atualmente, não existem trabalhos que esclareçam o processo de infecção de A. avenae subsp. citrulli em melão. A microscopia eletrônica de varredura foi utilizada por Frankle et al. (1993) para acompanhar a penetração e colonização de A. avenae subsp. citrulli em frutos de melancia.

O presente trabalho teve como objetivo estudar a penetração e colonização de $A$. avenae subsp. citrulli em folhas, frutos e sementes de melão, com o auxílio da microscopia eletrônica de varredura.

Sementes de melão do híbrido AF-646 foram plantadas em copos plásticos de $300 \mathrm{ml}$ contendo substrato organo-vegetal Plantmax ${ }^{\circledR}$. Após oito dias, as folhas verdadeiras foram pulverizadas até o escorrimento com a suspensão bacteriana do isolado Aac1 de A. avenae subsp. citrulli, com uma concentração de $3,4 \times 10^{7}$ UFC ml-1 em água destilada esterilizada adicionada de Tween 20 (0,01\%). A suspensão foi preparada a partir do crescimento bacteriano com 24-36 h em meio ágar nutritivo-extrato de leveduradextrose. As plantas foram submetidas à câmara úmida por $24 \mathrm{~h}$ antes e depois da inoculação, sendo mantidas em casa de vegetação. Amostras de tecido foliar de $25 \mathrm{~mm}^{2}$ foram coletadas nos períodos de 0, 24, 48, 72, 96 e 120 h após a inoculação com o patógeno. A amostra de zero h foi mantida em câmara úmida por apenas 30 min após a inoculação.

Frutos de melão do tipo Amarelo, sem sintomas, com 37 e 51 dias de idade, oriundos de plantios comerciais da região produtora de Mossoró-RN, foram lavados com sabão neutro em água corrente, deixados para secar a temperatura ambiente e demarcados em seis áreas quadrangulares/fruto medindo de 64-100 mm² (Frankle et al., 1993). Em cada área demarcada foram depositados $10 \mu \mathrm{l}$ da suspensão bacteriana e os frutos foram mantidos em câmara úmida e em B.O.D. (Biochemistry Oxygen Demand) a temperatura de $28 \pm 2{ }^{\circ} \mathrm{C}$. As amostras $\left(25 \mathrm{~mm}^{2}\right.$ de área e $2 \mathrm{~mm}$ de profundidade) de cada fruto nas diferentes idades foram retiradas em intervalos de 0, 24, 36, 48, 72 e 96 h após a inoculação. As amostras de zero h foram mantidas nas condições acima descritas por 2 h após a inoculação.

Sementes de melão do híbrido AF-646 foram lavadas em água corrente para a remoção do fungicida aplicado no tratamento comercial e deixadas para secar a temperatura ambiente. Após sete dias, foram imersas na suspensão bacteriana por 30 min e colocadas para secar em copos plásticos $(50 \mathrm{ml})$ perfurados, sobre papel absorvente a temperatura ambiente $\left(28 \pm 2{ }^{\circ} \mathrm{C}\right)$ por $24 \mathrm{~h}$. Após este período foram analisados os tegumentos externo e interno, o embrião e o endosperma da semente.

Para exame em microscópio eletrônico de varredura, as amostras de folhas, frutos e sementes foram fixadas com 2,5\% de glutaraldeído + 2,5\% de formaldeído diluídos em tampão cacodilato de sódio 0,05 M, pH 7,2 (Karnovsky, 1965) acrescido de $1 \mathrm{mM}$ de $\mathrm{CaCl}_{2}$ e armazenados durante sete dias nesta solução. Após essa etapa, as amostras foram submetidas a três lavagens de 15 min em tampão cacodilato 0,1 M seguidas de imersão em solução de tetróxido de ósmio $\left(\mathrm{OsO}_{4}\right)$ 1\% em tampão cacodilato $0,2 \mathrm{M} \mathrm{pH} \mathrm{7,2} \mathrm{por} 1 \mathrm{~h}$. As amostras pós-fixadas em $\mathrm{OsO}_{4}$ foram lavadas com água destilada e submetidas à desidratação em soluções com concentrações crescentes de etanol em água (30, 50, 70, 90 e $100 \%$ ) permanecendo por $10 \mathrm{~min}$ em cada uma, sendo que em etanol $100 \%$ as amostras foram submetidas a três trocas de 20 min cada. Em seguida, as amostras foram secas pelo método do ponto crítico do $\mathrm{CO}_{2}$ em aparelho BALTEC CPD 030 e, após montagem em suporte, recobertas por "sputtering" com aproximadamente $60 \mathrm{~nm}$ de ouro em aparelho MED 010 da BALZERS.

Para análise do interior da polpa dos frutos, foi utilizado o protocolo para criofratura adaptado por Kitajima \& Leite (1999). As amostras foram fixadas em fixador de Karnovsky modificado e tratadas com glicerol 30\% durante 30 min. Após estabilização das amostras e acessórios na temperatura do nitrogênio líquido, a polpa foi induzida à clivagem. As fraturas foram pós-fixadas e processadas conforme descrito anteriormente.

As amostras foram observadas no microscópio eletrônico de varredura LEO 435 VP, no Núcleo de Apoio à Pesquisa/Microscopia Eletrônica Aplicada à Pesquisa Agropecuária, da Escola Superior de Agricultura Luiz de Queiroz, da Universidade de São Paulo.

A microscopia eletrônica de varredura permitiu comprovar a colonização epifítica de A. avenae subsp. citrulli na superfície das folhas de melão. Nas amostras de zero h, foi detectada, conforme esperado, a presença $A$. avenae subsp. citrulli aderida a superfície da folha em baixa população. Contudo, nas amostras com 24, 48, 72, 96 e 120 h após a inoculação, observou-se uma crescente população de células bacterianas, mostrando a necessidade de algumas horas para que ocorra a colonização epifítica dos tecidos (Figura 1). A presença de bactérias não foi verificada na amostra testemunha (Figura 1A).

As células bacterianas, na maioria das vezes, estavam agregadas (Figura 1B) e muito raramente isoladas, localizadas predominantemente em áreas protegidas como flanges cuticulares (Figuras $1 \mathrm{~B}$ a $1 \mathrm{E}$ ), base dos tricomas (Figura 1E), ao redor dos estômatos (Figuras 1B a 1D) e nos poros estomáticos (Figura 1F). Esses eventos foram notados em relação a outras fitobacterioses por Getz et al. (1983) e Mariano et al. (1992). Verificou-se também a presença de fibrilas nas células de $A$. avenae subsp. citrulli interligando-as a superfície do hospedeiro (Figura 1C inset). Campbell et al. (1987) observaram a presença de material fibrilar, que proporcionou a aderência de Pseudomonas sp. aos tecidos de plântulas de canola. O papel da adesão superficial em interações envolvendo plantas e bactérias não é completamente conhecido. Contudo a adesão de bactérias fitopatogênicas a plantas suscetíveis tem sido considerada, em muitos casos, como um evento essencial no processo de infecção. Além disso, para que exerça um efeito significativo 


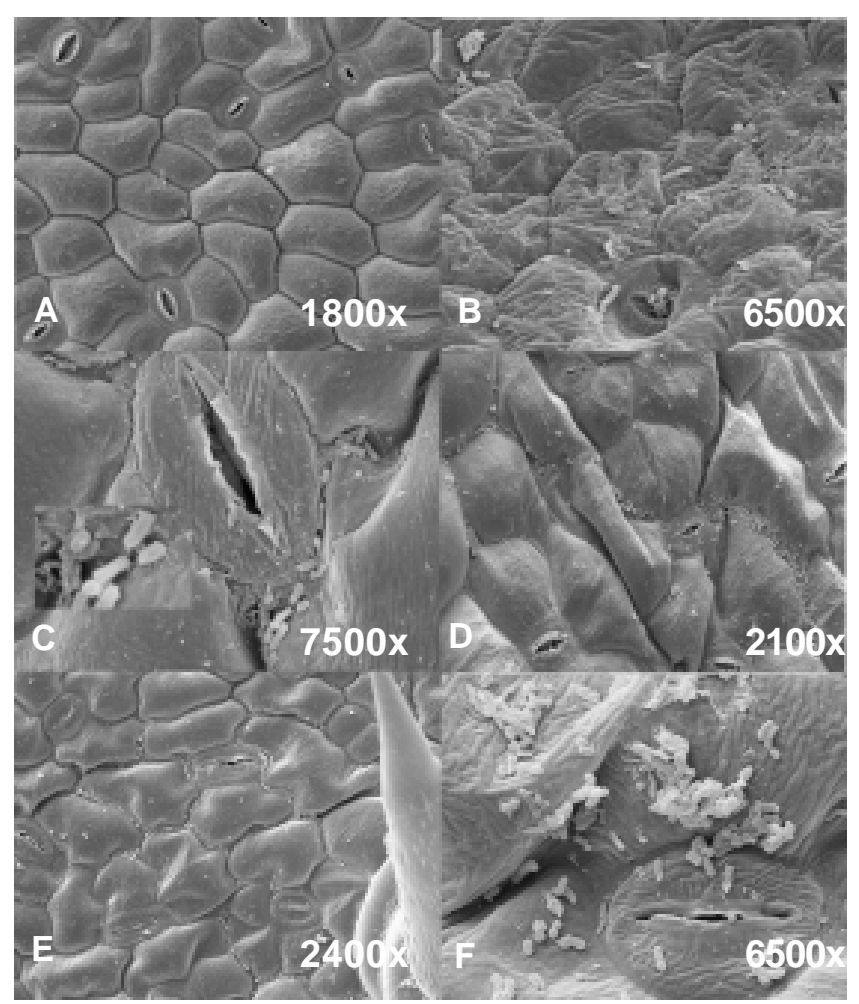

FIG. 1 - Microscopia eletrônica de varredura de folhas de meloeiro (Cucumis melo) com oito dias inoculadas com Acidovorax avenae subsp. citrulli. (A) Testemunha, evidenciando estômatos e células da epiderme; (B) Colonização dos tecidos 24 h após a inoculação; (C) Colônias ao redor e sobre o estômato 48 h após inoculação, fibrilas em detalhe; (D) Aspecto geral da folha colonizada $72 \mathrm{~h}$ após inoculação; (E) Observação de bactérias nas flanges cuticulares da folha e na base do tricoma 96 h após inoculação; (F) Colonização dos tecidos e penetração através dos estômatos da folha 120 h após a inoculação

sobre a fisiologia da planta hospedeira, as bactérias precisariam antes colonizar efetivamente a superfície (Romantschuk, 1992).

Evidências morfológicas indicam que A. avenae subsp. citrulli penetrou nas folhas de melão Amarelo via aberturas estomáticas (Figura 1F). Os estômatos, por ocorrerem em grande número, são tidos como as aberturas naturais mais importantes para penetração de fitobactérias que incitam enfermidades de parte aérea (Goodman, 1982). A penetração de A. avenae subsp. citrulli por estômatos concorreria para o desenvolvimento dos primeiros sintomas da mancha-aquosa, que se manifestam através de anasarcas no limbo foliar, seguidas de manchas de coloração marromescura.

Na superfície de frutos com 37 dias, poucas células bacterianas foram observadas nas amostras com zero h. Nas amostras coletadas 24 h após a inoculação foi verificada a presença da bactéria colonizando epifiticamente a casca, e concentradas ao redor de estômatos e lenticelas (Figuras 2A e 2B). Nas amostras com $48 \mathrm{~h}$ foi constatada a presença

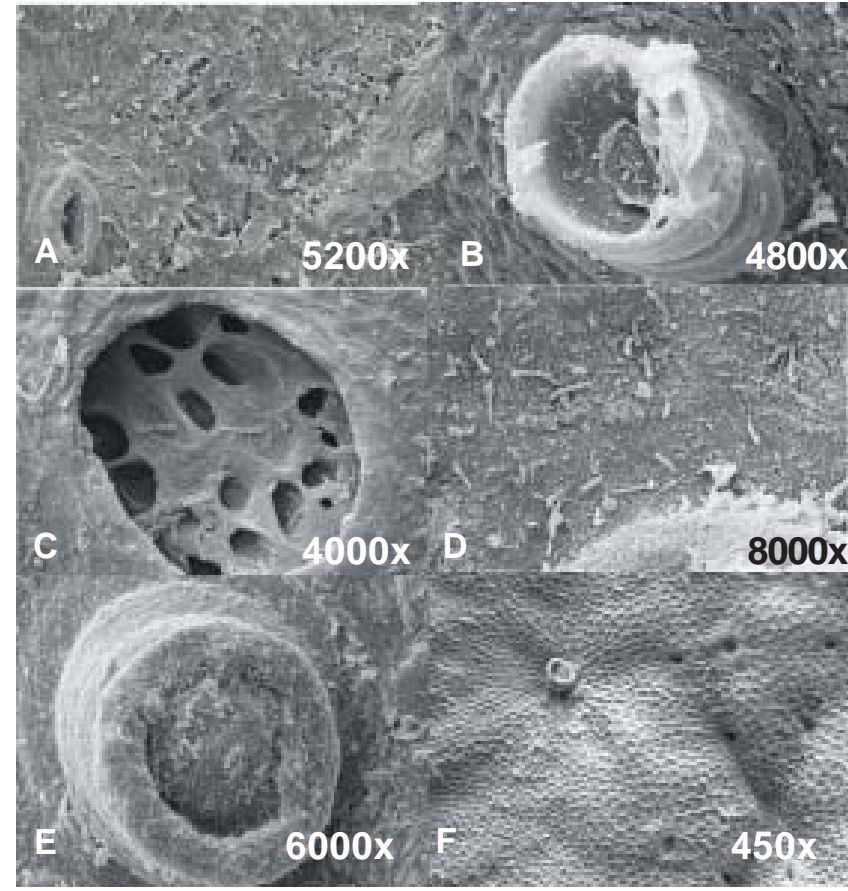

FIG. 2 - Microscopia eletrônica de varredura de tecidos de frutos de melão (Cucumis melo) inoculados com Acidovorax avenae subsp. citrulli. Frutos com 37 dias: (A) Colonização da superfície do fruto e penetração por estômatos 24 h após inoculação; (B) Detalhe da lenticela colonizada pela bactéria 24 h após inoculação; (C) Bactéria colonizando a polpa do fruto 48 h após inoculação. Frutos com 51 dias: (D) Colonização da superfície do fruto próximo a lenticela 24 h após a colonização; (E) Detalhe da lenticela colonizada por A. avenae subsp. citrulli 48 h após inoculação; (F) Testemunha evidenciando estômatos e lenticelas.

da bactéria na polpa do fruto (Figura 2C), demonstrando a rápida capacidade de penetração de A. avenae subsp. citrulli em frutos desta idade. Nas demais amostras (72 e 96 h) foram encontradas poucas ou até mesmo nenhuma bactéria na superfície. Novos estudos envolvendo mobilidade bacteriana poderiam indicar que as células bacterianas haviam penetrado em quase sua totalidade na polpa do fruto.

Nas amostras com zero h dos frutos com 51 dias de idade poucas células bacterianas foram encontradas na superfície. Expressiva colonização epifítica da superfície, estômatos e lenticelas foi constatada até 72 h após a inoculação (Figuras 2D e 2E). Na polpa dos frutos, a bactéria só foi encontrada nas amostras com 96 h, indicando uma penetração mais lenta em relação às amostras de frutos com 31 dias. Segundo Frankle et al. (1993) à medida que os frutos de melancia vão amadurecendo são cobertos com uma camada de cera que fecha os estômatos e previne a entrada de A. avenae subsp. citrulli. Provavelmente, o mesmo deve ocorrer com os frutos do melão.

Nas amostras testemunhas dos frutos com 37 e 51 dias não foram encontradas células bacterianas (Figura 2F). Frankle et al. (1993) estudaram a penetração de $A$. 
avenae subsp. citrulli em frutos de melancia com 14 a 21 dias, utilizando o método de deposição da suspensão na superfície dos frutos. Os autores observaram uma grande quantidade de células bacterianas ao redor dos estômatos, 24 h após a inoculação; dentro da câmara estomatal após 48 h; bem como poucas bactérias após 72 e 96 h, estando todas na câmara estomatal. Eles também verificaram que a quantidade de cera nos estômatos aumentou com a idade dos frutos, criando uma barreira morfológica à penetração da bactéria.

Na literatura só tem sido relatada a penetração de $A$. avenae subsp. citrulli em frutos através de estômatos. Contudo, evidências morfológicas indicam que esta bactéria penetrou nos frutos de melão Amarelo via lenticelas. Lenticelas são citadas como aberturas naturais através das quais as bactérias fitopatogênicas podem penetrar. Outras espécies bacterianas também penetram em seus hospedeiros através dessa estrutura. A deposição da suspensão de Pectobacterium sp. em tubérculo de batata (Solanum tuberosum L.) é suficiente para que a bactéria penetre via lenticelas e cause infecção (Ciampi et al., 1997).

Vinte e quatro horas após inoculação por imersão, células de A. avenae subsp. citrulli foram encontradas colonizando epifítica ou endofiticamente todas as partes das sementes analisadas: tegumentos externo e interno (Figuras 3A e 3B), embrião (Figura 3C) e endosperma (Figura 3D). Isto comprova a eficiência com que a bactéria penetra e coloniza a semente.

A semente é um dos principais agentes de disseminação de $A$. avenae subsp. citrulli. Assis et al. (1999) sugeriram que a introdução da mancha-aquosa no Rio Grande do Norte ocorreu por sementes contaminadas. Devese levar em consideração também que a semente é importante

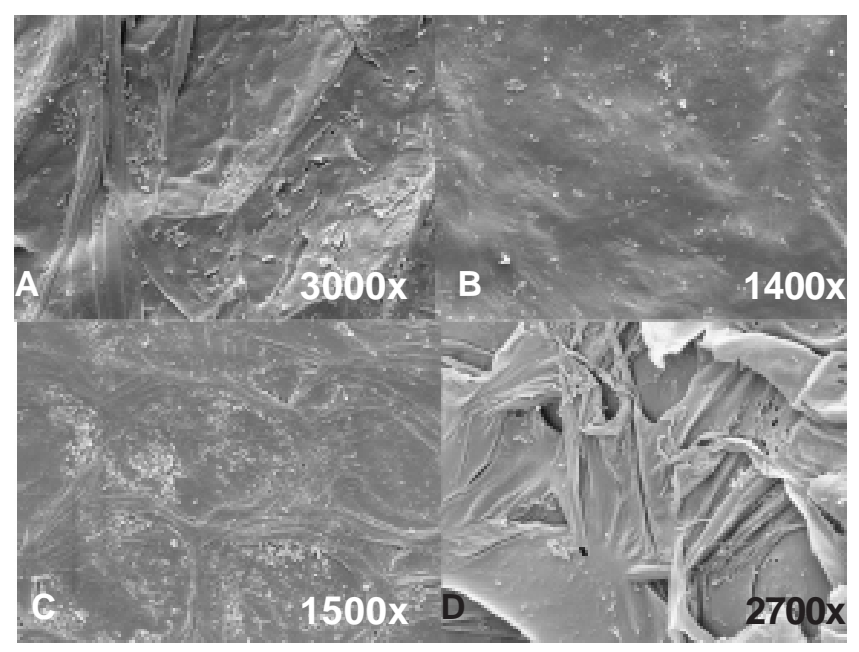

FIG. 3 - Microscopia eletrônica de varredura de sementes de melão (Cucumis melo) inoculadas com Acidovorax avenae subsp. citrulli e analisadas 24 h após inoculação. Patógeno colonizando: (A) Parte externa do tegumento; (B) Parte interna do tegumento; (C) Região do embrião; (D) Endosperma. no processo de sobrevivência de A. avenae subsp. citrulli, existindo relatos da manutenção do nível de transmissão da mancha-aquosa durante seis meses em sementes de melão armazenadas em condições de laboratório procedentes de frutos infectados de áreas produtoras de Mossoró (Oliveira et al., 2001). A localização da bactéria no endosperma e embrião dificulta o controle através de tratamentos físicos, químicos e biológicos (Mariano \& Silveira, 2004).

\section{AGRADECIMENTOS}

Os autores agradecem ao CNPq pela concessão de auxílio financeiro (Proc. 473024/2003-9) e bolsas de iniciação científica.

\section{REFERÊNCIAS BIBLIOGRÁFICAS}

ASSIS, S.M.P., MARIANO, R.L.R., SILVA-HANLIN, D.M.W. \& DUARTE, V. Mancha aquosa do melão causada por Acidovorax avenae subsp. citrulli, no Estado do Rio Grande do Norte. Fitopatologia Brasileira 24:191. 1999.

CAMPBELL, J.N., CASS, D.D. \& PETEYA, D.J. Colonization and penetration of intact canola seedling roots by opportunistic fluorescent Pseudomonas sp. and the response of host tissue. Phytopathology 77:1166-1173. 1987.

CIAMPI, L., BERNAL, G., VALENZUELA, N., ACUÑA, I. \& KALACICH, J. Estudios sobre la epidemiologia de Erwinia sp. I Efecto del saneamiento de plantas com pie negro sobre la calidad sanitaria de un semillero de papa (Solanun tuberosum L.). Fitopatología 32:144-153. 1997.

FRANKLE, W.G., HOPKINS, D.L. \& STALL, R.E. Ingress of watermelon fruit blotch bacterium into fruit. Plant Disease 77:1090-1092. 1993.

GETZ, S., FULBRIGHT, D.W. \& STEPHENS, C.T. Scanning electron microscopy of infection sites and lesion development on tomato fruit infected with Pseudomonas syringae pv. tomato. Phytopathology 73:39-43. 1983.

GOODMAN, R.N. The infection process. In: Mount, M.S. \& Lacy, G.H. (Eds.) Phytopathogenic prokaryotes. v.1. New York. Academic Press. 1982. pp.31-62.

INSTITUTO BRASILEIRO DE GEOGRAFIA E ESTATÍSTICA IBGE. Banco de dados agregados. Brasília. Sistema IBGE de Recuperação Automática - SIDRA. 2002. Disponível em: <http:/ /www.sidra.ibge.gov.br/bda/tabela/protabl.asp>. Acesso em: 29 jun. 2004.

KARNOVSKY, M.J. A formaldehyde-glutaraldehyde fixative of high osmolatily for use in electron microscopy. Journal of Cell Biology 27:137A-138A. 1965.

KITAJIMA, E.W. \& LEITE, B. Curso introdutório de microscopia eletrônica de varredura. 2 ed. Piracicaba. Núcleo de Apoio à Pesquisa em Microscopia Eletrônica Aplicada à Pesquisa Agropecuária/ESALQ. 1999.

MARIANO, R.L.R., McCARTER, S.M. \& PADOVAN, I.P. Utilização do fixativo de parducz para microscopia eletrônica de varredura de bactérias fitopatogênicas em tecido vegetal e cultura pura. Caderno Ômega: Série Agronomia 1:77-85. 1992.

MARIANO, R.L.R., SILVA, V.A.V., SILVA, A.M.F., MEDEIROS, 
F.H.V. \& VIANA, I.O. Ocorrência da mancha-aquosa na Bahia. Fitopatologia Brasileira 29:147-148. 2004 (Resumo).

MARIANO, R.L.R. \& SILVEIRA, E.B. Mancha-aquosa: importante bacteriose do meloeiro no Brasil. Anais da Academia Pernambucana de Ciência Agronômica 1:79-88. 2004.

OLIVEIRA, I.S., JÚNIOR, R.S. \& MARIANO, R.L.R. Acidovorax avenae subsp. citrulli: Métodos de isolamento e transmissão por sementes. Fitopatologia Brasileira 26:302. 2001 (Resumo).
ROMANTSCHUK, M. Attachment of plant pathogenic bacteria to plant surfaces. Annual Review of Plant Pathology 30:225-243. 1992.

SALES JÚNIOR, R. \& MENEZES, J.B. Mapeamento das doenças fúngicas, bacterianas e viróticas do cultivo do melão no Estado do RN. Mossoró. Escola Superior de Agricultura de Mossoró. Relatório Técnico. 2001.

SANTOS, A.A. \& VIANA, F.M.P. Mancha-aquosa do melão. Fortaleza. EMBRAPA-SPI. 2000. 